\title{
Laboreal
}

Volume 15 N$^{\circ} 2$ | 2019

Varia

\section{Semana de Saúde do Trabalhador de 14 a 19 de maio de 1979: um marco na história de uma luta contra a silicose no Brasil}

\section{Francisco Antonio de Castro Lacaz}

\author{
(2) OpenEdition \\ Journals \\ Edição electrónica \\ URL: http://journals.openedition.org/laboreal/15458 \\ DOI: $10.4000 /$ laboreal. 15458 \\ ISSN: 1646-5237 \\ Editora \\ Universidade do Porto \\ Refêrencia eletrónica \\ Francisco Antonio de Castro Lacaz, «I Semana de Saúde do Trabalhador de 14 a 19 de maio de 1979: \\ um marco na história de uma luta contra a silicose no Brasil », Laboreal [Online], Volume 15 №2 | 2019, \\ posto online no dia 01 dezembro 2019, consultado o 14 setembro 2020. URL : http:// \\ journals.openedition.org/laboreal/15458
}

Este documento foi criado de forma automática no dia 14 setembro 2020.

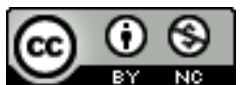

Laboreal está licenciado com uma Licença Creative Commons - Atribuição-NãoComercial 4.0 Internacional. 


\title{
I Semana de Saúde do Trabalhador de 14 a 19 de maio de 1979: um marco na história de uma luta contra a silicose no Brasil
}

\author{
Francisco Antonio de Castro Lacaz
}

No Brasil, o Ministério da Saúde, pela Portaria $n^{\circ} 1.984$, datada de 12 de setembro de 2014, define lista de doenças de notificação compulsória, dentre elas a silicose. Já para o extinto Ministério da Previdência Social ${ }^{[1]}$ a exposição à sílica é prevista no Decreto $\mathrm{n}^{\mathrm{o}}$ 3.048, de 06/05/1999, que definiu diversas atividades com risco de exposição à sílica e a doenças relacionadas à exposição, dentre elas a silicose. Em 06/02/2007, o Decreto $n^{\circ}$ 6.042, alterou o Regulamento da Previdência Social, aprovado pelo referido Decreto 3.048. Assim, o Decreto $\mathrm{n}^{\circ} 6.042$ apresenta uma lista dos agentes causadores de doenças profissionais ou do trabalho, conforme previsto no $\operatorname{art}^{\circ} 20$ da Lei $n^{\circ} 8.213$ de 1991. Nos casos em que o reconhecimento previdenciário ocupacional da silicose não é aceito pelo empregador nem pela Previdência Social, resta ao trabalhador buscar a Justiça do Trabalho para obter indenização por danos materiais e morais. A indenização por dano material, é prevista pelo Código de Processo Civil, sendo dividida em três situações: a) indenização no caso de morte do doente ( $\operatorname{art}^{\circ} 948$, Código Civil); b) indenização no caso de incapacidade temporária (artº 949, Código Civil); c) indenização no caso de incapacidade permanente, total ou parcial ( $\operatorname{art}^{\mathrm{a}}$ 950, Código Civil). No caso de indenização por incapacidade permanente devido à silicose, parcial ou total, a legislação prevê, além da cobertura das despesas para o tratamento até o retorno ao trabalho, o pagamento de pensão mensal em valor proporcional aos danos sofridos pela vítima ou à sua inabilitação profissional. Muitos trabalhadores com silicose podem receber benefícios previdenciários, mas existe demora na definição pericial pelo nexo, além de ocorrer um número excessivo de avaliações periciais para estabelecimento do nexo ocupacional em trabalhadores com silicose (Fernandes, 2017). 
2 Essa base legal teve origem no final dos anos 1970. Era o momento das grandes greves operárias que abalaram as estruturas da ditadura civil-militar brasileira, após o fim do chamado "milagre econômico" (Singer, 1976).

3 Naquela época, havia no Brasil cerca de 150 mil trabalhadores expostos cotidianamente ao pó de sílica, sendo que destes, 30 mil apresentavam comprometimento pulmonar pela silicose, doença que levava invariavelmente, à morte. Dentre estes estavam os trabalhadores da extração de carvão e minérios de pedreiras; da escavação de túneis; de indústrias metalúrgicas; das fábricas de sabões e materiais abrasivos. Além destes, uma das categorias mais afetadas era a dos trabalhadores das indústrias de cerâmica e louças onde observa-se altas temperaturas e o ar é dominado pelo pó de sílica (Rebouças, 1989).

4 O Sindicato dos Ceramistas da cidade de Jundiaí, no interior do estado de São Paulo, enfrentava a silicose desde o início dos anos 1970. Foi uma luta pioneira no “(...) contexto do movimento sindical da época" (Rebouças, 1989, p. 206).

5 Ocorre que o problema somente passou a ser considerado pelos trabalhadores ceramistas daquela cidade quando o então presidente do Sindicato “(...) associou as queixas dos operários à doença, num Congresso da Previdência Social, durante uma palestra sobre pneumoconioses. Dirigentes e trabalhadores desconheciam a silicose, fato que ainda persiste em vários lugares do Brasil" (Rebouças, 1989, p. 206-207).

6 Apesar da omissão das empresas, muitos trabalhadores ceramistas queixavam-se com frequência de tosse seca, cansaço e falta de ar o que apontava para um estágio já avançado da doença. Havia uma grande dificuldade para o Sindicato comprovar a doença e avançar na luta. Era preciso realizar exames que a confirmassem e muitos médicos confundiam-na com tuberculose com a qual podia associar-se ou com pneumonia. Diante disso, o Sindicato procurou a Santa Casa da Misericórdia de São Paulo onde atuavam médicos especialistas em doenças pulmonares.

7 Mesmo com o diagnóstico firmado por exames de função pulmonar e Raios X dos pulmões realizados pelos dois especialistas, as centenas de trabalhadores com silicose, quando encaminhados para o Instituto Nacional de Previdência Social (INPS) para obtenção de afastamento do trabalho e auxílio-doença frustravam-se, pois:

(...) muitas vezes os peritos do INPS recusavam o diagnóstico de silicose (...) de 1971 a 1976, o Sindicato constatou 311 casos de silicose entre os ceramistas (...) O número de casos registrados (...) poderia ter sido bem maior não fosse o medo de represálias por parte dos patrões. Quando o empregador descobria que alguém estava doente fazia de tudo para demiti-lo (Rebouças, p. 208).

8 Esta situação começa a mudar no final dos anos 1970, quando o foco da luta dos ceramistas também mudou. Ocorreram muitas reuniões no Sindicato dos Ceramistas de Jundiaí com a participação de médicos militantes, nas quais chegaram à conclusão que era preciso:

(...) buscar a mudança do ambiente de trabalho e o (...) fim da doença, ao invés de apenas garantir os direitos previdenciários. (...) as pressões dos empresários eram mais fortes que o Sindicato (...). As represálias contra a organização dos trabalhadores se repetiam o tempo todo, incentivadas pelo regime autoritário da época (Rebouças, 1989, p. 208). 

deu origem a uma maior organização da luta sindical por melhores condições de trabalho e em defesa da saúde, no Brasil, ainda sob o regime militar (Ribeiro \& Lacaz, 1984).

Dado que o problema da silicose acometia várias categorias como já foi dito, a luta iniciada pelos ceramistas de Jundiaí mobilizou também os trabalhadores das indústrias metalúrgicas e construção civil que em 1978 criaram “(...) um grupo de trabalho sobre a doença [silicose] constituído por dirigentes sindicais, médicos, advogados e engenheiros. O grupo transformou-se na Comissão Intersindical de Saúde dos Trabalhadores (Cisat). Já no ano seguinte, 1979, a Cisat organizou a I Semana de Saúde do Trabalhador - I Semsat" (Rebouças, 1989, p. 208).

11 A primeira Semsat teve como tema de discussão justamente as "Poeiras e as doenças pulmonares". A I Semsat foi realizada em várias cidades do país no período de 14 a 19 de maio de 1979. Representou o primeiro momento de efetiva articulação dos sindicatos de trabalhadores para discutir e propor medidas de prevenção contra as doenças pulmonares do trabalho pois uma delas, a silicose, já registrava entre 20 a $30 \mathrm{mil}$ trabalhadores afetados (Ribeiro \& Lacaz, 1984).

12 Numa realidade de repressão ao movimento sindical pela ação da ditadura civil-militar, dentre as Conclusões da I Semsat publicadas no livro De que Adoecem e Morrem os Trabalhadores, organizado por Ribeiro e Lacaz, em 1984, são dignas de nota as seguintes, as quais apontam para o crônico descaso empresarial para com o problema, assim como a omissão da Universidade e da Previdência Social:

\footnotetext{
“As condições dos ambientes de trabalho, (...) para trabalhadores sujeitos ao pó de sílica, asbestos, algodão (...) são reconhecidamente precárias. Dessas condições resultam doenças pulmonares graves, irreversíveis e progressivas" (Ribeiro \& Lacaz, 1984, p. 39, grifos introduzidos).

“Os estudos e pesquisas sobre essas doenças são raros, quando não $\underline{\text { inexistentes, }}$ caracterizando a desatenção das Escolas Médicas e instituições $\underline{\text { de pesquisa brasileira para o problema" (Ribeiro \& Lacaz, 1984, p. 39, grifos }}$ introduzidos).

“As doenças pulmonares provocadas pelo ambiente de trabalho incapacitam parcial ou totalmente milhares de trabalhadores brasileiros, encurtando suas vidas, marginalizando-os social e economicamente, recaindo o ônus sobre as próprias vítimas ou sobre a sociedade (...) como um todo" (Ribeiro \& Lacaz, 1984, p. 39, grifos introduzidos).

"A instabilidade no emprego, o desconhecimento dos perigos a que estão expostos pelas poeiras, a falta de organização das bases, a ausência de liberdade e autonomia sindicais, são obstáculos para que a classe trabalhadora assuma esse papel de defesa de sua saúde" (Ribeiro \& Lacaz, 1984, p. 40, grifos introduzidos).
}

13 Quanto às Recomendações são relevantes, por sua abrangência ético-social e forte caráter de enfrentamento dos interesses do Capital:

"Reconhecimento da insalubridade de todas as atividades que liberem poeiras minerais ou orgânicas, independente de inspeções técnicas" (Ribeiro \& Lacaz, 1984, p. 40, grifos introduzidos).

"Fixação de um prazo para que todas as empresas cujas atividades produzam poeiras adotem as medidas preventivas necessárias em relação ao ambiente de trabalho" (Ribeiro \& Lacaz, 1984, p. 40, grifos introduzidos).

Laboreal, Volume 15 N$^{\circ} 2$ | 2019 
"Redução da jornada de trabalho e proibição de regime de horas extras para os trabalhadores sujeitos às poeiras de sílica, asbesto, algodão (...), através de contrato coletivo, por indústria, realizado com o sindicato, até que sejam adotadas $\underline{\text { medidas preventivas, }}$, cientificamente comprovadas, ..." (Ribeiro \& Lacaz, 1984, p. 40, grifos introduzidos).

"Proibição do trabalho do menor de 18 anos e da mulher nos ambientes sujeitos a poeiras capazes de produzir doenças pulmonares irreversíveis" (Ribeiro \& Lacaz, 1984, p. 40, grifos introduzidos).

14 É importante assinalar que a luta sindical iniciada contra a silicose em Jundiaí trouxe progresso na redução de casos da doença, pois sua ocorrência diminuiu pela metade e as empresas passaram a realizar exames mais frequentemente, entregando os resultados aos trabalhadores (Rebouças, 1989).

Ademais, um importante desdobramento desta luta pioneira foi a criação, em 1980, por dezenas de sindicatos de trabalhadores, do Departamento Intersindical de Estudos e Pesquisas de Saúde e dos Ambientes de Trabalho (Diesat) que existe até hoje, apesar de mais frágil em suas ações, em função da crise de representação sindical em todo o mundo ocidental.

\section{BIBLIOGRAFIA}

Fernandes, M. de C. (2017). Asma relacionada ao trabalho e silicose: avaliação pericial no INSS de casos diagnosticados em ambulatório especializado entre 2005 e 2015 (dissertação de mestrado profissional). Fundação Jorge Duprat Figueiredo de Segurança e Medicina do Trabalho (Fundacentro), São Paulo.

Rebouças, A.J. (1989). Insalubridade: morte lenta no trabalho. São Paulo: Oboré Editorial/Diesat.

Ribeiro, H.P. \& Lacaz, F.A. (1985, Orgs.) De que adoecem e morrem os trabalhadores. São Paulo: Imprensa Oficial do Estado/Diesat.

Singer, P. I. (1976). A crise do "Milagre": interpretação crítica da economia brasileira. Rio de Janeiro: Paz e Terra [2ª . edición]

\section{NOTAS}

1. O Ministério da Previdência Social foi extinto pelo atual governo brasileiro e as atribuições anteriormente por ele assumidas foram transferidas para o Ministério da Economia, demonstrando o caráter financista dos direitos sociais assumido pelo governo Bolsonaro. 


\section{AUTOR}

FRANCISCO ANTONIO DE CASTRO LACAZ

Departamento de Medicina Preventiva da Escola Paulista de Medicina da Universidade Federal de São Paulo, Rua Botucatu, 740 - 4º. Andar, CEP 04023-900, São Paulo, São Paulo

franlacaz@hotmail.com 